\title{
Using the step by step models to evaluate field application uniformity of subsurface drip irrigation systems
}

\section{Hiba Ghazouani ${ }^{1},{ }^{*}$, Basma Latrech ${ }^{1}$, Mguidich Belhaj Amel $^{2}$, Boutheina M'hamdi Douh ${ }^{1}$, Ghazouani Issam $^{3}$ and Abdelhamid Boujelben $^{1}$}

\author{
${ }^{1}$ Department of Rural Engineering. Higher Institute of Agronomy. Chott-Mariem \\ Sousse (ISA-CM). Université de Sousse, 4042. Tunisia. *Email: \\ ghazouani_hibaunipaisa@yahoo.com. \\ ${ }^{2}$ Regional Field Crops Research Center (CRRGC). Béja. Tunisia. \\ ${ }^{3}$ University of Jendouba. Higher School of Agriculture of Kef. Kef. Tunisia.
}

\begin{abstract}
Compared to other irrigation methods, drip irrigation systems (DI) are considered one of the most efficient form of irrigation. Subsurface drip irrigation allowed reducing water losses by evaporation, runoff, and deep percolation comparing to other irrigation systems supplying water on soil surface. Field evaluation of Uniformity of water applications and its stability, however, are still a matter of controversy and deserve more investigation, since the collection of water discharged needs to excavate the soil around the emitters. Experiments carried out at the Department of Rural and Agrifood Engineering of Polytechnic University of Valencia allowed describing a methodology to assess the performance of drip irrigation through hydraulic characterizations and an emission uniformity coefficient, using the step by step models. Calculations evidenced that operating pressures on emitters ranged between $127.6 \mathrm{kPa}$ and $131.7 \mathrm{kPa}$, whereas the corresponding flow rates varied from $4.00 \mathrm{~L} / \mathrm{h}$ and $4.07 \mathrm{~L} / \mathrm{h}$, with an average value of $4.02 \mathrm{~L} / \mathrm{h}$. Variability in the emitters' flow rate resulted very limited due to the short length of the lateral $(25.6 \mathrm{~m})$. However, more attention should be paid to this for a longer field dimensions. Consequently, the value of emission uniformity coefficient was equal to $96.3 \%$, testifying the uniform water distribution within the sub-plot.
\end{abstract}

Keywords: Field uniformity; Coefficient of variation; Flow variation; Laboratory SBS.
Received

March 10, 2019

Accepted

April 29, 2019

Released

April 30, 2019

Full Text Article

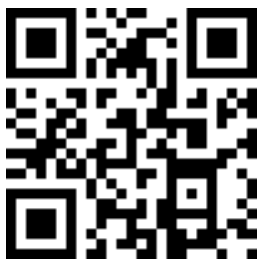

ORCID

D 0000-0002-4601-1528

Hiba Ghazouani

(D) 0000-0002-5790-0558

Basma Latrech

(ㄱ) 0000-0002-1223-5312 Mguidich Belhaj Amel

(D) 0000-0002-3439-2212

Boutheina M'hamdi Douh

(ㄷ) 0000-0002-7797-2671

Ghazouani Issam

(1) 0000-0002-3026-9014

Abdelhamid Boujelben 


\section{Introduction}

Population is in continuous increase and the amelioration of people's living standard will lead to increase in food demand in the near future. Most of this food need will be met by the irrigated agriculture. At the same time, projections predict a decrease of water input per unit irrigated area in response to water scarcity and environmental concerns region (Schultz, 2000; Chaves et al., 2007; IPCC, 2007). In that context comes the necessity of improving water use efficiency (Madramootoo and Fyles, 2010). The first step in optimizing the efficiency of any irrigation management program is to make sure that the irrigation system is well chosen and designed (Ghazouani, 2017). Irrigation scheduling and uniformity are two key factors for increasing water plant profits. Irrigation scheduling aims to determine the correct timing and amount of water, necessary for maintain root moisture within the optimal range for crop growth Irrigation uniformity, in adverse, is related to how equal water is distributed over the field area. Compared to other irrigation methods, drip irrigation systems (DI) are considered one of the most efficient form of irrigation. Subsurface drip irrigation allowed reducing water losses by evaporation, runoff, and deep percolation comparing to other irrigation systems supplying water on soil surface (Camp, 1998; Alizadeh, 2001; ASAE, 2005). According to the American Society of Agricultural and Biological Engineers (ASABE, 2007), SDI allows "application of water below the soil surface through emitters, with discharge rates generally in the same range of the drip irrigation". In addition, the annual replacement of system components, necessary for traditional drip irrigation systems, increases the irrigation cost and reduce the gross margin of the producer (Camp et al., 1997). In contrast, the emitters clogging by roots, soil particles, and ions disturb the flow rate of the emitter of subsurface drip systems (Camp, 1998; Ayars et al., 1999). However, In order to achieve a satisfactory performance, any irrigation system should ensure the water distribution uniformity, that depends on friction and local losses, land slope, emitter sensitivity to pressure and temperature variations, emitter quality, as well as emitter clogging. Moreover, under subsurface drip irrigation systems, emitter flow rate can also be affected by soil properties. In particular soil topography and friction losses, among other factors, influence the relationship between flow rate, $Q$, and operating pressure, P:

$$
Q=k P^{x}
$$

Where: $k$ and $x$ are two coefficients depending on the emitter model.

The manufacturer coefficient of variation, $\mathrm{CV}$, is a measure of the variability of emitter flow rate at a certain operating pressure. This coefficient is therefore related to the manufacturing quality and it is usually determined before installation to avoid ageing effect (ASABE, 2007). However, under field condition and after use the emitters could change their performance, with unavoidable consequences on water uniformity.

A number of coefficients have been used to express field distribution uniformity. In addition to Christiansen's (1942) Coefficient (UC), the Karmeli and Keller (1975) coefficient, EU, the statistical coefficient of variation, $\mathrm{CV}$, and the low quarter distribution uniformity coefficient, $\mathrm{DU}_{\mathrm{lq}}$ (Kruse, 1978), have been largely used. All these coefficients reproduce the uniformity of the water distributed across a field, accounting for the variability of discharges associated to the emitter's hydraulic characteristics and possible clogging, as well as field topography. A Qualitative standard 
classification, have been developed by ASAE (2005) based on manufacturer's coefficient of emitter variation (CV). ASAE (2005) reported that CV values below $10 \%$ are considered suitable and more than $20 \%$ are unacceptable. Moreover, the emitter discharge variation rate (qv) should be evaluated as a design criterion in drip irrigation systems; qv bellow $10 \%$ may be regarded as good and qv more than 20\% as unacceptable (Wu and Gitlin, 1979; Camp et al., 1997).

However, field evaluation of these parameter requires measurement of emitter flow rate and pressure at selected locations throughout the field. This can be easily done for traditional DI systems where the emitters are located on the soil surface; it is much more complicated for SDI systems, because the collection of water discharged needs to excavate the soil around the emitters to be evaluated. Moreover, Sadler et al. (1995) evidenced that excavating the emitter increased the flow rate between $2.8 \%$ and $4.0 \%$. For these reasons, models for design and evaluation of drip irrigation systems, such as the Step by Step (SBS) procedure, may be used to evaluate field application uniformity of subsurface systems (Wu and Gitlin, 1979).

The main objective of this study, is to describe laboratory procedure aiming to evaluate the performance of subsurface drip irrigation system through hydraulic characterizations and an emission uniformity coefficient and to test and its dependence on operation pressure and tape length.

\section{Material and methods}

Experiments were carried out on a drip irrigation system supposed to be implemented on four plots (treatments $\mathrm{T} 1, \mathrm{~T} 2, \mathrm{~T} 3$ and T4) in order to investigate the effects of two different water qualities and two different irrigation regimes. Treatments $\mathrm{T} 1$ and $\mathrm{T} 2$ were irrigated with good water quality, whereas treatments $\mathrm{T} 3$ and $\mathrm{T} 4$ with saline water. All investigated treatments were subjected to the same seasonal crop management, except that for irrigation doses; in particular, treatments T1 and T3 were maintained under full irrigation, in order to supply the volumes corresponding to the maximum crop evapotranspiration estimated between consecutive watering. On the other hand, treatments $\mathrm{T} 2$ and $\mathrm{T} 4$ received approximately the half of irrigation volumes provided in $\mathrm{T} 1$ and $\mathrm{T} 3$. The geometric features (pipe internal diameter, emitter spacing, diameter and length); the hydraulic characteristics, i.e. the flow rate-pressure head relationship, $\mathrm{q}(\mathrm{h})$ and the manufacturing coefficient of variation, $\mathrm{CV}$, usually considered for the quantitative evaluation of the emitters' quality (Solomon, 1979), have been determined according to the Step by step models (SBS). Both the $\mathrm{q}(\mathrm{h})$ relationship and the CV value were evaluated by testing a sample of 25 emitters by following ISO 9261:2004 (ISO, 2004). The value of CV was determined as:

$$
C V=\frac{\sigma}{q_{m}}
$$

where $\sigma[\mathrm{L} / \mathrm{h}]$ is the standard deviation of the flow rates of the examined emitters' sample and $\mathrm{q}_{\mathrm{m}}[\mathrm{L} / \mathrm{h}]$ is the arithmetic mean of individual emitter discharges.

Experiments were carried out at the Department of Rural and Agrifood Engineering of Polytechnic University of Valencia, by using the installation shown in Figure 1. 

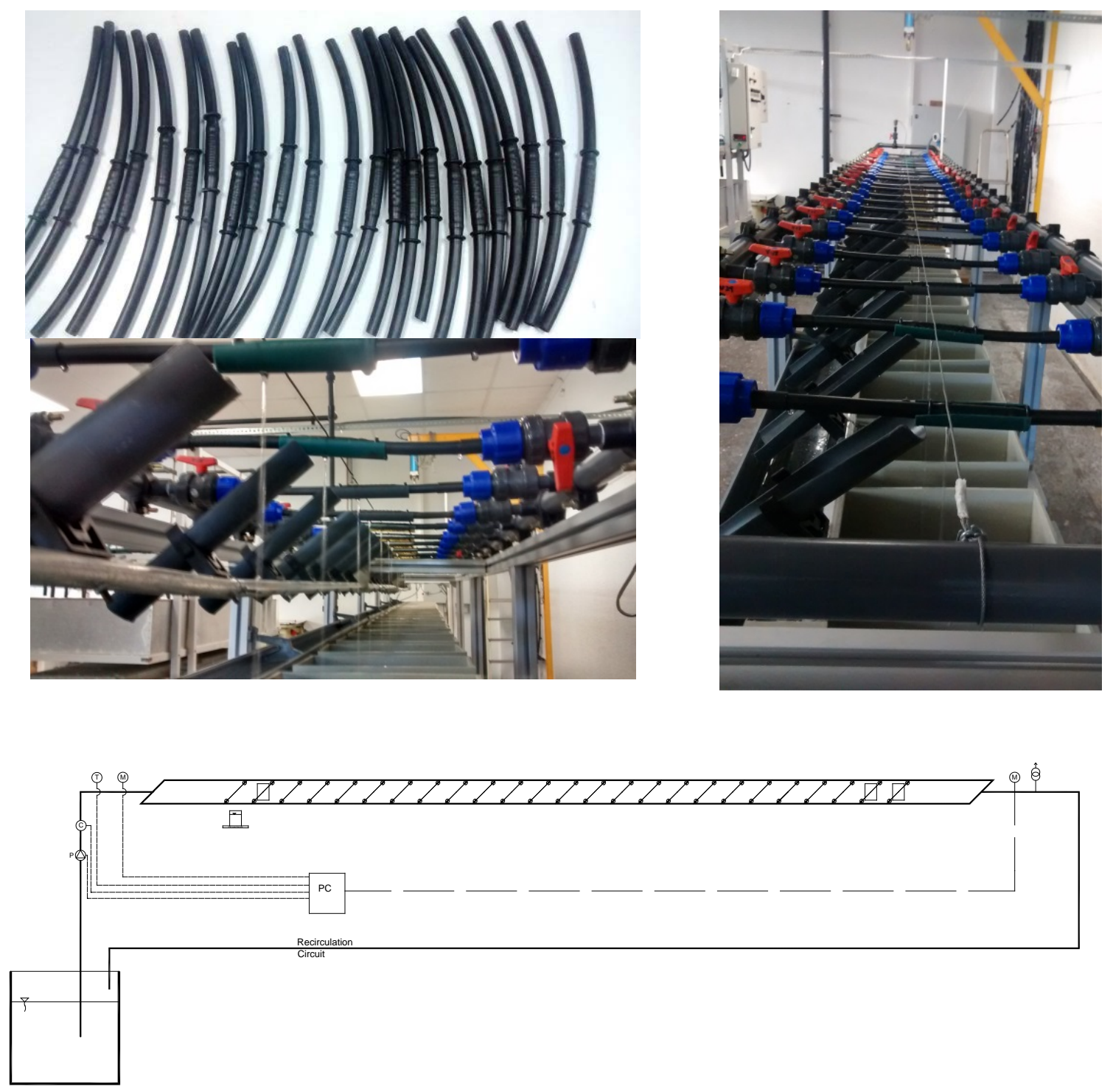

Figure 1. Images of the tested trams of drip laterals and of the test bench used for the emitters' hydraulic characterization. In the lower part is shown the schematic layout of installation.

Twenty-five trams of pipe $(25 \mathrm{~cm}$ length), randomly selected from a $200 \mathrm{~m}$ long coextruded lateral and containing one emitter, were tested. Initially, the internal diameter of the pipes and the emitters were measured. The former, $D_{i}$, was measured by using ten $30 \mathrm{~cm}$ long pipe samples that were weighted by a precision balance before and after filling the sample with distilled water of a known temperature. The same methodology was used to measure the internal emitter diameter, $\mathrm{D}_{\mathrm{g}}$, whereas the emitters length, $\mathrm{Lg}_{\mathrm{g}}$ were measured by a precision Vernier caliper (Provenzano and Pumo, 2004).

All the selected trams of drip pipe were inserted between two PVC pipes having nominal diameter ND $=32 \mathrm{~mm}$. Two pressure gauges (P1, P2) with a precision of $1.0 \mathrm{hPa}$ and one thermometer with a precision of $0.1{ }^{\circ} \mathrm{C}$ were installed in the circuit, in order to monitor the pressure and the water temperature during the experiments. All the tests were carried out by maintaining 
the water at a temperature of $23{ }^{\circ} \mathrm{C} \pm 3{ }^{\circ} \mathrm{C}$ and by using clear water, filtered through a 150 mesh filter.

The circuit was fed and pressurized by an electrical pump fitted with a pressure control system. The test was performed after flushing the sample with clean water in order to wash the powder that could have been inside the labyrinth. After conditioning the circuit for a total of $1.0 \mathrm{~h}$, according to the step by step models suggested by ISO 9261:2004 (ISO, 2004), the emitter flow rates were measured, by weight, at pressures of 49.7, 94.0, 138.1, 182.4, 226.7, 271.2 and $315.8 \mathrm{kPa}$. Individual emitter discharges were determined by weighting the volume of water flushed for 15 min inside collector containers in which load cell sensors (precision of 0.01 g) were installed. The measured water temperature allowed to account for the actual water density. All the load sensors, pressure gauge and thermometer were interfaced to a personal computer, specifically programmed in LabVIEW, for the data acquisition and the subsequent analysis. For each pressure value applied to the circuit, the standard deviation of flow rate was also evaluated in order to verify the emitter quality according to the manufacturing variation's coefficients.

Once known the dripline geometric and hydraulic characterization it was possible to evaluate the field distribution uniformity coefficient, EU [\%], based on the definition proposed by Karmeli and Keller (1975):

$$
E U=100\left[1-1.27 \frac{C V}{\sqrt{N}}\right]\left(\frac{Q_{\min }}{Q_{a v g}}\right)
$$

Where: CV is the emitter manufacturer's variation coefficient, $\mathrm{N}$ is the number of emitters per plant, $Q_{\text {min }}$ and $Q_{\text {avg }}$ are minimum and average emission rates in the subplot, respectively.

The step by step procedure (Provenzano and Pumo, 2004), starting from the downstream end of the last lateral and proceeding to the upstream end of the sub-plot network, allowed the evaluation of operating pressure head and the actual flow rate corresponding to each emitter, based on the field topography, the effective dripline geometry, as well as the $\mathrm{q}(\mathrm{h})$ relationship experimentally evaluated.

\section{Results and discussion}

Table 1 shows the pipe nominal diameter (ND) and the nominal flow rate as indicated by the manufacturers $(\mathrm{Qn})$, the mean, $\mu$, and standard deviation, $\sigma$, of measured pipe (Di) and emitter (Dg) internal diameters and emitter length (Lg) as well as the net spacing between emitters, $\mathrm{S}$, and the value of $\mathrm{Di} / \mathrm{Dg}$ ratio.

Table 1. Pipe nominal diameter, ND, nominal flow rate, $\mathrm{Q}_{\mathrm{n}}$, mean, $\mu$, and the standard deviation, $\sigma$, of $D_{i}, D_{g}$ and $L_{g}$; the values of the emitter spacing $S$ and the ratio $D_{i} / D_{g}$ are also indicated.

\begin{tabular}{c|c|cc|cc|cc|c|c}
\hline $\mathbf{N D}$ & $\mathbf{Q}_{\mathbf{n}}$ & \multicolumn{2}{|c|}{$\mathbf{D}_{\mathbf{i}}$} & \multicolumn{2}{|c|}{$\mathbf{D}_{\mathbf{g}}$} & \multicolumn{2}{|c|}{$\mathbf{L}_{\mathbf{g}}$} & $\mathbf{S}$ & $\mathbf{D}_{\mathbf{i}} / \mathbf{D}_{\mathbf{g}}$ \\
\hline$[\mathrm{mm}]$ & {$[\mathrm{L} / \mathrm{h}]$} & $\begin{array}{c}\mu \\
{[\mathrm{mm}]}\end{array}$ & $\begin{array}{c}\sigma \\
{[\mathrm{mm}]}\end{array}$ & $\begin{array}{c}\mu \\
{[\mathrm{mm}]}\end{array}$ & $\begin{array}{c}\sigma \\
{[\mathrm{mm}]}\end{array}$ & $\begin{array}{c}\mu \\
{[\mathrm{mm}]}\end{array}$ & $\begin{array}{c}\sigma \\
{[\mathrm{mm}]}\end{array}$ & {$[\mathrm{mm}]$} & {$[\mathrm{mm}]$} \\
\hline 16 & 4.0 & 11.86 & 0.15 & 11.50 & 0.12 & 68.0 & 1.9 & 332 & 1.031 \\
\hline
\end{tabular}

Table 2 shows the weight of water flushed in 15 min from the tested emitters under different water pressures. The values of manufacturer coefficient variation, $\mathrm{CV}$, and the average flow rates, $\mathrm{Q}_{\mathrm{m}}$, are also indicated at the bottom of the table. As can be observed, for a fixed pressure, the weight of discharged 
volumes and therefore the emitter flow rates of different emitters were not constant due to the slight differences caused by the manufacturing process. However, considering that the coefficient of variation resulted on average equal to $2.6 \%$, for the examined operating pressures and in line with the criterion proposed by Solomon (1979), the emitters' quality can be classified as excellent ( $\mathrm{CV} \leq 3.0 \%$ ).

Figure 2 shows the experimental values of emitters flow rate, $\mathrm{Q}[\mathrm{L} / \mathrm{h}]$, and the corresponding operating pressure, $\mathrm{P}$ $[\mathrm{kPa}]$, indicated in table 3.6 , as well as the related fitting curve, having equation:

$$
Q=0.337 P^{0.5105}
$$

Table 2. Weight of water flushed in $15 \mathrm{~min}$ from the tested emitters under different operating pressures. The values of manufacturer coefficient variation, $\mathrm{CV}$, and the average flow rates, $\mathrm{Q}_{\mathrm{m}}$, are also indicated at the bottom of the table.

\begin{tabular}{|c|c|c|c|c|c|c|c|c|c|c|}
\hline Pressure $[\mathrm{kPa}]$ & 99.6 & 49.7 & 94.0 & 138.1 & 182.4 & 226.7 & 271.2 & 315.8 & 359.7 & 359.6 \\
\hline Time [s] & 900 & 900 & 900 & 900 & 900 & 900 & 900 & 900 & 900 & 900 \\
\hline Temperature $\left[{ }^{\circ} \mathrm{C}\right]$ & 21.7 & 21.9 & 22.0 & 22.1 & 22.2 & 22.1 & 22.1 & 22.2 & 22.3 & 22.3 \\
\hline \multirow[t]{2}{*}{ Emitter } & \multicolumn{9}{|c|}{ Weight of emitted water } & \\
\hline & [g] & [g] & [g] & [g] & [g] & [g] & [g] & [g] & [g] & [g] \\
\hline 1 & 888.00 & 622.14 & 861.65 & 1053.08 & 1211.97 & 1353.40 & 1479.90 & 1594.50 & 1704.54 & 1705.08 \\
\hline 2 & 877.54 & 617.72 & 852.66 & 1037.32 & 1197.54 & 1343.09 & 1471.74 & 1584.20 & 1696.53 & 1695.39 \\
\hline 3 & 916.52 & 644.59 & 893.60 & 1082.77 & 1251.37 & 1397.37 & 1528.28 & 1651.99 & 1765.37 & 1768.13 \\
\hline 4 & 892.91 & 631.15 & 866.69 & 1053.63 & 1215.18 & 1361.83 & 1491.11 & 1605.57 & 1715.16 & 1716.80 \\
\hline 5 & 882.22 & 619.04 & 857.29 & 1046.69 & 1204.95 & 1343.71 & 1472.78 & 1588.72 & 1697.21 & 1695.58 \\
\hline 6 & 910.04 & 634.60 & 878.59 & 1080.67 & 1243.74 & 1385.90 & 1522.20 & 1634.97 & 1753.27 & 1753.56 \\
\hline 7 & 855.97 & 591.99 & 828.95 & 1017.99 & 1168.49 & 1301.18 & 1428.24 & 1536.20 & 1641.53 & 1641.08 \\
\hline 8 & 884.67 & 616.20 & 860.64 & 1048.31 & 1208.24 & 1348.46 & 1472.35 & 1591.81 & 1696.42 & 1699.18 \\
\hline 9 & 881.41 & 621.68 & 858.75 & 1038.24 & 1204.88 & 1341.41 & 1461.34 & 1581.31 & 1687.56 & 1688.80 \\
\hline 10 & 877.46 & 616.81 & 853.13 & 1037.46 & 1199.30 & 1333.22 & 1462.08 & 1575.72 & 1683.39 & 1683.99 \\
\hline 11 & 910.73 & 632.66 & 885.38 & 1086.26 & 1244.98 & 1386.92 & 1525.65 & 1643.78 & 1759.19 & 1757.18 \\
\hline 12 & 841.89 & 588.25 & 816.36 & 999.18 & 1144.96 & 1284.99 & 1404.25 & 1513.01 & 1620.62 & 1618.86 \\
\hline 13 & 872.05 & 608.28 & 843.71 & 1031.42 & 1187.40 & 1328.27 & 1453.51 & 1564.77 & 1673.98 & 1673.35 \\
\hline 14 & 902.54 & 629.96 & 880.92 & 1063.13 & 1225.06 & 1375.75 & 1508.28 & 1630.44 & 1742.99 & 1745.21 \\
\hline 15 & 863.13 & 606.00 & 840.39 & 1024.91 & 1183.41 & 1317.48 & 1442.93 & 1553.96 & 1664.02 & 1664.54 \\
\hline 16 & 50.79 & 597.49 & 825.70 & 1013.07 & 1166.20 & 1300.32 & 1420.14 & 1528.50 & 1637.73 & 1635.81 \\
\hline 17 & 851.99 & 595.76 & 826.10 & 1009.75 & 1163.53 & 1297.68 & 1422.63 & 1533.17 & 1642.34 & 1639.90 \\
\hline 18 & 863.12 & 606.55 & 840.33 & 1016.52 & 1176.67 & 1311.71 & 1436.13 & 1549.84 & 1658.74 & 1659.55 \\
\hline 19 & 859.40 & 604.67 & 834.46 & 1013.87 & 1171.84 & 1308.27 & 1431.68 & 1544.72 & 1652.77 & 1653.00 \\
\hline 20 & 916.26 & 642.69 & 891.14 & 1091.42 & 1254.16 & 1399.19 & 1533.83 & 1655.46 & 1768.13 & 1766.48 \\
\hline 21 & 905.39 & 631.36 & 875.05 & 1076.47 & 1236.55 & 1376.56 & 1509.88 & 1624.14 & 1742.29 & 1741.85 \\
\hline 22 & 889.51 & 617.10 & 861.51 & 1056.33 & 1212.65 & 1356.24 & 1486.66 & 1602.33 & 1713.56 & 1710.29 \\
\hline 23 & 913.32 & 634.08 & 885.19 & 1082.41 & 1247.30 & 1393.98 & 1526.23 & 1647.30 & 1759.49 & 1759.77 \\
\hline 24 & 880.26 & 622.05 & 859.19 & 1040.39 & 1205.13 & 1345.76 & 1467.11 & 1585.03 & 1696.16 & 1697.19 \\
\hline 25 & 859.74 & 602.17 & 834.27 & 1016.59 & 1175.85 & 1309.24 & 1437.13 & 1550.78 & 1658.66 & 1658.49 \\
\hline Average weight [g] & 881.87 & 617.40 & 856.47 & 1044.71 & 1204.05 & 1344.08 & 1471.84 & 1586.89 & 1697.27 & 1697.16 \\
\hline St. Dev. [g] & 22.52 & 15.65 & 22.16 & 27.39 & 30.84 & 34.53 & 38.68 & 42.14 & 44.58 & 44.97 \\
\hline CV [-] & 2.55 & 2.54 & 2.59 & 2.62 & 2.56 & 2.57 & 2.63 & 2.66 & 2.63 & 2.65 \\
\hline $\mathrm{Q}_{\mathrm{m}}[\mathrm{l} / \mathrm{h}]$ & 3.53 & 2.47 & 3.43 & 4.18 & 4.82 & 5.38 & 5.89 & 6.35 & 6.79 & 6.79 \\
\hline
\end{tabular}




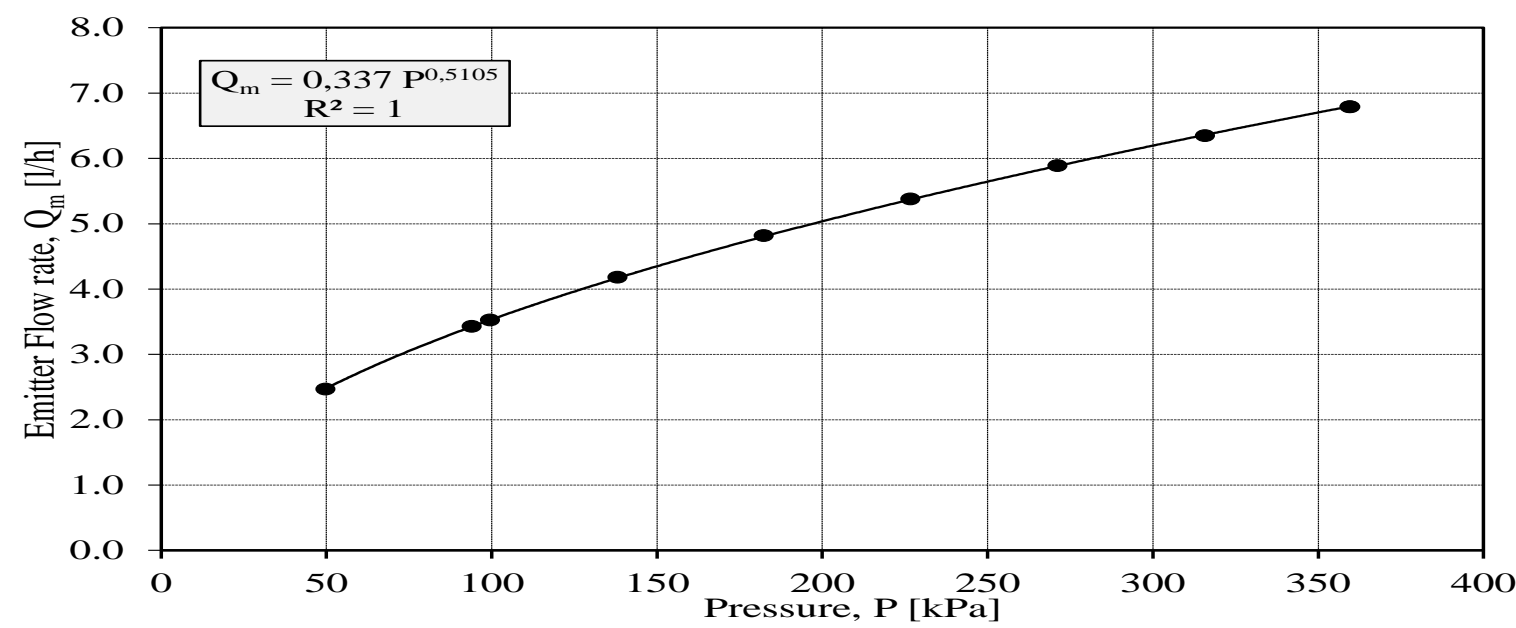

Figure 2. Flow rate as a function of operating pressure for the emitters used in the experiments.
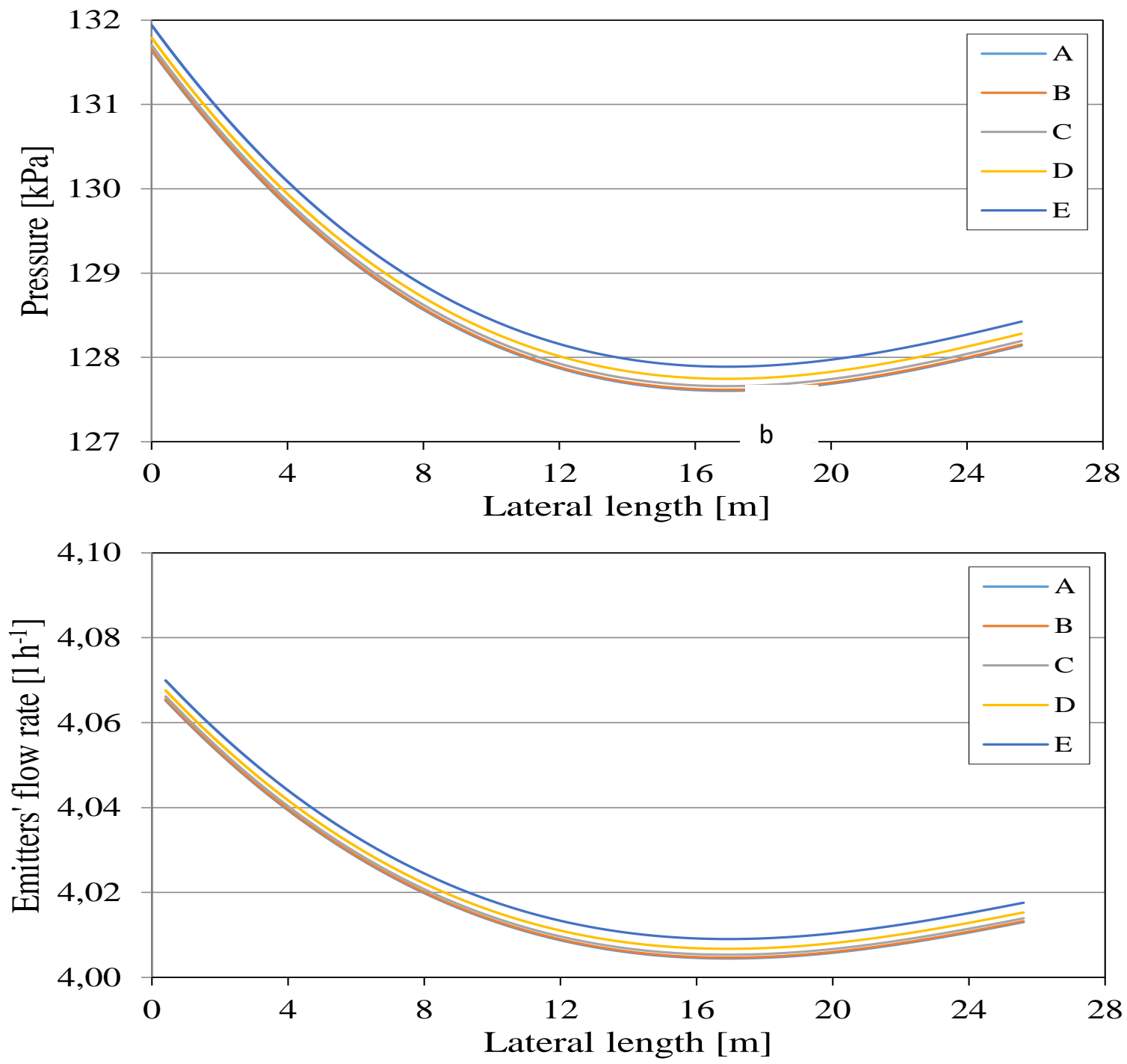

Figure 3. Operating pressures (a) and emitters flow rate (b) as a function of the lateral length. Letters in legend indicate drip laterals in the sub-plot, from the last $(A)$ to the first $(E)$. 


\section{Discussion}

It was verified from table 2 that, the nominal flow rate of $4.0 \mathrm{~L} / \mathrm{h}$ is discharged at pressure of $127.3 \mathrm{kPa}$ and not at the pressure of $100 \mathrm{kPa}$ as usually considered. Moreover, by increasing the operating pressure from $50 \mathrm{kPa}$ to 200 $\mathrm{kPa}$, the discharge values rise from 2.5 $\mathrm{L} / \mathrm{h}$ to $5.0 \mathrm{l} / \mathrm{h}$. In order to distribute the correct amount of water through the field, it is therefore very important to control operating pressures during irrigation. Karmeli and Keller (1975) emission uniformity coefficient, EU, was evaluated based on the step by step (SBS) procedure, applied on each subplot distribution network, consisting of five drip laterals (ND 16) and a submain pipe (ND 32). The procedure, implemented in an excel spreadsheet, allowed to take into account soil topography, dripline and submain geometric and hydraulic characteristics, as well as pipe friction losses and local losses due to the emitters' connections. Figure 3 shows the operating pressures and the corresponding emitters' flow rate (b) versus the lateral length, obtained for the five drip laterals (from the last, A to the first, E) installed in treatment $\mathrm{T} 1$, by assuming an operating pressure at the downstream end of last drip lateral equal to $128.1 \mathrm{kPa}$.

The performed calculations evidenced that operating pressures on emitters installed in the sub-plot (treatment T1) ranged between 127.6 $\mathrm{kPa}$ and $131.7 \mathrm{kPa}$, whereas the corresponding flow rates varied from $4.00 \mathrm{~L} / \mathrm{h}$ and $4.07 \mathrm{~L} / \mathrm{h}$, with an average value of $4.02 \mathrm{~L} / \mathrm{h}$. The theoretical limited variability in the emitters' flow rate is due to the short length of the lateral $(25.6 \mathrm{~m})$ and to the small pressure losses in the laterals and in the submain pipe. Consequently, the value of emission uniformity coefficient evaluated by equation 3 , equal to $96.3 \%$, reflected the fairly uniform water distribution within the sub-plot.

\section{Conclusion}

Subsurface irrigation has been the focus of attention mainly because of its low evaporation rate and deep percolation losses. Uniformity of water applications and its stability, however, are still a matter of controversy and deserve more investigation. Experiments carried out at the Department of Rural and Agrifood Engineering of Polytechnic University of Valencia allowed to describe how to assess the performance of a drip irrigation through hydraulic characterizations and an emission uniformity coefficient, using the step by step models. The performed calculations evidenced that operating pressures on emitters ranged between $127.6 \mathrm{kPa}$ and $131.7 \mathrm{kPa}$, whereas the corresponding flow rates varied from $4.00 \mathrm{~L} / \mathrm{h}$ and 4.07 $\mathrm{L} / \mathrm{h}$, with an average value of $4.02 \mathrm{~L} / \mathrm{h}$. The theoretical limited variability in the emitters' flow rate is due to the short length of the lateral $(25.6 \mathrm{~m})$ and to the small pressure losses in the laterals and in the sub main pipe. Since, more attention should be paid to this limited variation for a longer field dimensions. Consequently, the value of emission uniformity coefficient was equal to $96.3 \%$, reflected the fairly uniform water distribution within the sub-plot.

\section{Conflict of interest}

The authors declare that there is no conflict of interest.

\section{References}

Alizadeh, A. Principles and practices of trickle irrigation. Mashad, Iran: Ferdowsi University, 2001.

ASABE - American Society of Agricultural and Biological Engineers. Annual Meeting. 2007. https://doi.org/10.13031/2013.23357

ASAE - American Society of Association Executives. Standards EP405.1 FEB03 - 
Design and Installation of Microirrigation Systems. St. Joseph, Michigan: ASAE, 2005.

Ayars, J. E.; Phene, C. J.; Hutmacher, R. B.; Davis, K. R. Schoneman, R. A.; Vail, S. S.; Mead, R. M. Subsurface drip irrigation of row crops: A review of 15 years of research at the Water Management Research Laboratory. Agricultural Water Management, v. 42, no. 1, p.1-27, 1999. https://doi.org/ 10.1016/S0378-3774(99)00025-6

Camp, C. R. Subsurface drip irrigation: A review. Transactions of the ASAE, v. 41, no. 5, p. 1353-1367, 1998. https://doi.org/ 10.13031/2013.17309

Camp, C. R.; Sadler, E. J.; Busscher, W. J. A comparison of uniformity measure for drip irrigation systems. Transactions of the ASAE, v. 40, p.1013-1020, 1997. https://doi.org/10.13031/2013.21353

Chaves, M. M.; Santos, T. P.; Souza, C. R.; Ortuño M. F.; Rodrigues M. L.; Lopes, C. M.; Maroco, J. P.; Pereira, J. S. Deficit irrigation in grapevine improves water-use-efficiency without controlling vigour and production quality. Annals of Applied Biology, v. 150, no. 2, p. 237-252, 2007. https://doi.org/ 10.1111/j.1744-7348.2006.00123.x

Christiansen, J. E. Irrigation by sprinkling. California Agricultural Experiment Station Bulletin, no. 670, 1942.

Ghazouani, H. Using infrared thermography and simulation models for the evaluation of water and salt stress: Application to micro irrigated horticultural crops. Sousse, Tunisia: Higher Agronomic Institute of Chott Meriem, 2017. (PhD thesis).

IPCC - Intergovernmental Panel on Climate Change. Climate Change 2007: The physical science basis. Contribution of Working Group I to the Fourth Assessment Report of the Intergovernmental Panel on Climate Change. Geneva: IPCC, 2007. (Synthesis report).

ISO - International Standard Organization. ISO 9261:2004(E) - Agricultural irrigation equipment-emitters and emitting pipes: Specification and test methods. Geneva: ISO, 2004.

Karmeli, D.; Keller, J. Trickle irrigation design. Glendora, California: Rain Bird Sprinkler Manufacturing Corp., 1975.

Kruse, E. G. Describing irrigation efficiency and uniformity. Journal of Irrigation and Drainage Division, v. 104 , no. 1 , p. $35-41$, 1978.

Madramootoo, C. A.; Fyles, H. Irrigation in the context of today's global food crisis. Irrigation and Drainage, v. 59, p. 40-52, 2010.

Provenzano, G.; Pumo, D. Experimental analysis of local pressure losses for microirrigation laterals. Journal of Irrigation and Drainage Engineering,

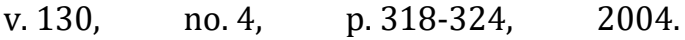
https://doi.org/10.1061/(ASCE)07339437(2004)130:4(318)

Sadler, E. J.; Camp, C. R.; Busscher, W. J. Emitter flow rate changes caused by excavating subsurface microirrigation tubing. Proceedering of the 5th Internatoinal Microirrigation Congress, St. Joseph, Michigan, p. 763-768, 1995.

Schultz, H. R. Climate change and viticulture: A European perspective on climatology, carbon dioxide, and UV-B effects. Australian Journal of Grape and Wine Research, v. 6, no. 1 , p. 2-12, 2000 . https://doi.org/ 10.1111/j.1755-0238.2000.tb00156.x

Solomon, K. H. Manufacturing variation of emitters in trickle irrigation systems. Transaction of the ASAE, v. 22, no. 5, p. 1034-1038, 1979. https://doi.org/ $10.13031 / 2013.35150$

Wu, I.-P.; Gitlin, H. M. The manufacturer's coefficient of variation of emitter flow for drip irrigation. Manoa: University of Hawaii, 1979. (U.S.D.A. Cooperating: 1-3). 